Mirjana I. Detelić

detelic.mirjana5@gmail.com

Lidija D. Delić

lidijab@ptt.rs

\title{
Modelativni potencijal kletve u usmenoj epici*
}

\begin{abstract}
Detelić Mirjana I., Delić Lidija D., Modelativni potencijal kletve u usmenoj epici (On the Modelative Potentials of the Curse in Oral Epics). „Poznańskie Studia Slawistyczne” 3. Poznań 2012. Adam Mickiewicz University Press, pp. 29-43. ISBN 978-83232-2473-0. ISSN 2084-3011.

This paper offers an analysis of (prevalently feminine) curses which come to being within the text of the epic songs. This specific form of cursing is particularly pointed in the curses by mother's milk. Both in tradition and in the epics, these curses are equal to taboo, which means that nobody dares disobey them: such is the deep belief in their efficiency. Because there is no discrimination in the epics about who can or cannot make a curse (everybody can: narrator/singer, protagonists, antagonists, heroes and their foes, messengers, mothers, wives, godmothers, sisters, brothers, fairies, forests, etc.), focusing on the parental and lovers' curse is necessary for the sake of congruence. This will help in spotting the interactive patterns in the structure of epic songs more accurately. The analysis is done on the corpus of approximately 1500 epic songs described at the end of this paper.
\end{abstract}

Keywords: oral epic poetry, functions of the curses, mother's curse, mother's milk, parent's curse, girl's curse

\section{1. ,Vodi roba, Džaferbegovice! - Ne bio ti dugo ni za mlogo!”}

U usmenoj epici, i usmenom stvaralaštvu uopšte, spektar kletvi izuzetno je širok, i kada je reč o modusima proklinjanja (kunu i narator/pevač i likovi u pesmi, protagonisti i antagonisti), i kada je reč o ulogama/domenima/tipovima likova (proklinju junaci i protivnici junaka, glasnici, majke,

* Rad je nastao u okviru projekata „Jezik, folklor, migracije na Balkanu” (br. 178010) i Srpsko usmeno stvaralaštvo u interkulturnom kodu (br. 178011), koje finansira Ministarstvo prosvete i nauke Republike Srbije. Iz datog korpusa izdvojeni su primeri koji reprezentuju tipske situacije/funkcije, u meri koju su diktirale propozicije obima rada. 
ljube, kume, sestre, pobratimi, vile, gora), i kada je reč o onome na koga je ili na šta je kletva usmerena (to može biti osoba, neprijatelj ili srodnik, ali i grad, konj, oružje, deo tela, duša, pleme, porod itd. $)^{1}$. Iako se delotvornost kletve u tradicionalnim kulturama ne dovodi u pitanje, epske kletve razlikuju se i po efektima koje izazivaju (ostvarene i neostvarene), ali i po opsegu na koji pretenduju. One najčešće pogađaju lice u vezi s kojim su izrečene, ali se mogu širiti u vremenu - i u prošlost i u budućnost, na pretke i potomke - za šta je eklatantan primer kletva sluge Milutina upućena Vuku Brankoviću:

A što pitaš za prokletog Vuka,
Proklet bio i ko ga rodio!
Prokleto mu pleme i koljeno!

On izdade cara na Kosovu

I odvede dvanaest hiljada,

Gospo moja! Ljutog oklopnika

(Vuk II, 45: 199-204).

Slično tome, domen kletvi širi se i van granica (ovozemaljske) ljudske egzistencije:

Kogođ sa mnom na udarac ne će,

Proklet bio na oba svijeta!

Ama ćemo, braćo, izginuti,

Da se kaže u pošljedno vrime

(Vuk IV, 54: 233-236)

${ }^{1}$ Žanrovski status/Žanrovska priroda kletve u usmenom stvaralaštvu, podela kletvi, njihova sintaksička struktura i njihove jezičke/komunikacijske funkcije neće biti predmet ovog rada. O datim aspektima dosta je pisano, korisni pregledi dati su u: T. Петровић, Природа клетве и њене комуникацијске функиије у српском језику, „Српски језик студије српске и словенске” бр. 2/1-2, 1997, стр. 87-95; Д. Перић, Клетва - поетска врста и(ли) реторички жанр, у: Жанрови српске књижевности: зборник радова, бр. 3, ур. 3. Карановић, Нови Сад 2006, стр. 67-85; С. Самарџија, Пословище, благослови и клетве у усменој књижевности, „Књижевност и језик” бр. 55/1-2, 2008, стр. 13-45; Љ. Суботић, Синтаксичко-семантичка структура клетви у епским народним песмама, „Српски језик - студије српске и словенске” бр. 13/1-2, 2008, стр. 137-148. Van analitičkog vidokruga biće i njihovi sociološki, etnološki i psihološki aspekti (Љ. Радуловачки, Клетва као сочијална категорија и психолошка одредница, Београд-Сремска Митровица 2001; L. Radulović, Roditeljska kletva kao nevidljivo nasilje: diskurs antimaterinstva u tradicijskoj kulturi, „Etnoantropološki problemi” br. 2/2, 2007, str. 137-146). 
što potvrđuje i analogna forma blagoslova:

Ja sam tebi dala obilježje,

Moj Hasane trista madžarija.

Ako si ih u piću popio,

Halal ti je na obadva svita.

Ako si se odužio duga

Te ti ih je dužnik prefatio,

Halal ti je na obadva svita.

Ako si ih na ženu metnuo,

E da Bog da ti je poželio,

Brzo tebi Ninka na um pala

(EH 10: 244-253; Cf. MH III, 4: 323)².

Iako u usmenoj epici kletve/formule „Proklet bio na oba svijeta!” i „Prokleta ti duša!” imaju dosta uopšteno, nekonkretizovano značenje, signali koje pokojnici pod kletvom šalju sa onoga sveta ukazuju na to šta se pod ukletošću ,na drugom svetu” podrazumeva. Po svemu sudeći, radi se o nemogućnosti „upokojenja”, smirenja duše umrlog/umrle, na šta upućuju i replika zaručnice Laza Radanovića, koju je (iako nedužnu!) majka proklela na polasku iz roda, i replike mladićā koje stižu devojačke kletve. U oba slučaja, one se pokazuju težima od smrti i zemlje:

majčina kletva

Često Lazo na grob izlazio,

Pa je pit'o svoju zaručnicu:

„Jel' ti, dušo, zemlja doteščala?"

Devojka mu mrtva odgovara:

„Nije meni zemlja doteščala,

Već je teška materina kletva"

(Vuk II, 07: 151-156). devojačka kletva

Umre Konda jedini u majke, Žao majci Kondu zakopati, Zakopati daleko od dvora, Već ga nosi u zelenu bašču, Te ga kopa pod žutu neranču. Svako ga je jutro oblazila: „Sine Konda, jel' ti zemlja teška? Il' su teške daske javorove?" Progovara Konda iz zemljice:

„Nije meni, majko, zemlja teška,

Nit' su teške daske javorove,

${ }^{2}$ Iz istog kompleksa predstava derivirana je i zakletva „obadva mi svita” (EH 1, 2, 3, 4, $5,6,7,8,10,12 ;$ MH IV, 30, 37) i kletva „,rn vam/im/ti obraz na obadva svita” (KH III 1; MH III, 23, 25; MH IV, 32, 46; MH IX, 17 i sl.). 


\section{Već su teške kletve devojačke:}

Kad uzdišu, do Boga se čuje;

Kad zakunu, sva se zemlja trese;

Kad zaplaču, i Bogu je žao!"

(Vuk I, 368).

Stabilna struktura proklinjanja/kletve - koja podrazumeva izricanje $\mathrm{i}$ ispunjenje $-\mathrm{u}$ tradiciji je prepoznata kao efektan (i ekonomičan) način povezivanja određenih segmenata radnje. Kao vrsta ponavljanja (govora kao radnje) ona je i mnemotehničko i kompoziciono sredstvo, a kao logička struktura, zasnovana na arhaičnim predstavama o moći reči i neminovnosti ispunjenja, kletva je i sredstvo nagoveštaja i objašnjenja epskih zbivanja. I kletve sa sasvim specifikovanim značenjem, i one opštijeg, ponekad i kolokvijalnog tipa, u pesmama dobrih pevača po pravilu se realizuju, te predstavljaju svojevrsne stožere epske priče:

\section{kletva}

Kupuje ga Turkinja đevojka,

Daje zanjga dva tovara blaga:

Ona ode da donese blago,

Vrag donese bulu udovicu,

Udovicu, Džaferbegovicu,

Dade zanjga tri tovara blaga,

I tri konja, šta će nosit' blago.

Ljuto kune Turkinja đevojka:

„Vodi roba, Džaferbegovice!

Ne bio ti dugo ni za mlogo,

Već, il' noćcu, ili noći dvije!"'

(Vuk III, 02: 28-38).

Ali majka kune bez prestanka:

\section{realizacija}

Gruica Novaković odista nakon noći provedene s Džaferbegovicom sa skupocenim odelom, konjem, oružjem i blagom beži u goru.
Ćerku na putu kroz goru stiže urok, ona umire i svatovi je u gori sahranjuju ${ }^{3}$.

\footnotetext{
${ }^{3}$ Cf. pesmu Ženidba Milića barjaktara, sa istovetnim motivom smrti neveste u gori od uroka:

Tu li tebe suđen danak nađe!

Ni kod moga ni kod tvoga dvora,

Ni kod moje ni kod tvoje majke

Već u gori pod jelom zelenom!

(Vuk III, 78: 185-188).
} 
Mila kćeri, i tebe ne bilo!

Ni doprla tamo, ni ovamo!

Već ostala sredi gore čarne

(Zaručnica Laza Radanovića;

Vuk II, 07: 99-102).

Ema veli sirota Roksandra: „Hajt' otole, Bož’ji prokletnici! Đavoli vi ponijeli dušu,

A oganj ve izgorio živi! Pa ve voda mutna ćerdosala!" (Dušan hoće sestru da uzme; Vuk II, 27: 74-78).
Ćelija u kojoj su zatvoreni grešni kaluđeri izgori, pod njom se provali zemlja i javi mutna voda (,,A otide Stefan na ćeliju, / Al' ćelija bješe izgorela, / I zemlja je pod njom izgorela, / Izgorela, pa se propanula, / Pa je voda udarila mutna, / Te je njine kosti ćerdosala"; 128-133).

Zahvaljujući pomenutoj logici, forma kletve uključivana je (naknadno) i u određene obrasce pevanja kao najširi kompozicioni okvir. Tako je, recimo, tema dugogodišnjih i teških muka umirućeg grešnika, u tradiciji vezana za lik Duke Senkovića/Šetkovića, asocirala mehanizam proklinjanja i krug pesama o grešnom sinu koji nakon ženidbe majku proteruje u goru. U pesmi iz zbirke Matice hrvatske o patnjama i smrti Duke Šetkovića (MH I, 39) majčina kletva, isprovocirana sinovljevim bezočnim postupkom, apsorbovala je ceo obrazac pevanja o velikom grešniku, sa svim motivima po kojima se on prepoznaje - teške i duge bolesti (devet godina), raspadanja živog tela, zemlje i mora koji izbacuju kosti grešnika, upokojenja atipičnim ritualom i na htonskom mestu (gore „izvanjskije”, „kamo ljudska stopa ne dopire").

Kletva kao tumačenje i (makar formalni) generator zbivanja nadilazi povremeno strukturu pojedinačne pesme, obuhvatajući širu usmenu predaju. Njome se u usmenoj epici objašnjavaju kontradiktorni elementi u okviru epskih biografija i događaji širih epsko-istorijskih razmera, za šta su eklatantni primeri sudbine Marka Kraljevića i porodice Branković, a - posredstvom ove poslednje - i sudbine srpske despotovine. Detalji Markovog epskog životopisa (smrt bez groba) i kontroverzna pozicija poslednjeg srpskog srednjovekovnog kralja, koji je bio sultanov vazal (a u epici još i sultanov posinak i turski pobratim) i, s druge strane, ključni 
nacionalni heroj, usmeni pevači tumačili su kletvom Markovog oca, kralja Vukašina, i blagoslovom njegovog epskog kuma - cara Uroša:

„Sine Marko, da te Bog ubije!

Ti nemao groba ni poroda!

I da bi ti duša ne ispala,

Dok Turskoga cara ne dvorio!"

Kralj ga kune, car ga blagosilja:

„Kume Marko, Bog ti pomogao!

Troje lice sv'jetlo na divanu!

Tvoja sablja sjekla na mejdanu!

Nada te se ne našlo junaka!

Ime ti se svuda spominjalo,

Dok je sunca i dok je mjeseca!"

Što su rekli, tako mu se steklo

(Uroš i Mrnjavčevići, Vuk II, 34: 246-257).

Slično tome, slom srpske države viđen je kao posledica kneževe kletve (posredovane i glasom sluge Milutina), bačene na „seme" Vuka Brankovića, čiji je sin - Đurađ Branković (†1456) - bio praktično poslednji srpski vladar (Smederevo je palo u turske ruke 1459. godine), a praunuk Jovan ( $† 1502)$ nominalno poslednji srpski despot (mada bez despotovine). Iako po formi drugačija, po pomenutim simboličkim implikacijama kneževu kletvu varira i kletva koju Maksim Branković (Grgurević) izriče u trenutku kada Jerina, protiv njegove volje, kćer daje turskom caru:

„Bog t' ubio, moja stara bako!

Kud je dala, u z'o čas je dala!

S njome dala zemlju i gradove!"

${ }^{4}$ U vezi s ovim stihovima Nikola Banašević govori o „proročanstvu unazad" (Н. Банашевић, Циклус Марка Краљевића и одјеции франиуско-талијанске витешке књижевности, Скопље 1935, стр. 19); oni su svojevrsna rekapitulacija istorijsko-epske zbilje, kao i stihovi iz pesme Čije je carstvo, gde se epska i istorijska realnost predstavljaju kao posledica Vukašinove i Markove kletve. Д. Ајдачић, Прилог проучавању клетви у усменој књижевности, u: idem, Прилози проучавању фолклора Балканских Словена, Београд 2004. 
Kako reče, onako se steče:

Dade ćerku za Otmanovića,

I s njom dade zemlju i gradove

(Vuk II, 80:40-45) ${ }^{5}$.

Kletva/prokletstvo se, dakle, u usmenoj epici generiše retroaktivno, post festum, onda kada se uspostavi određena istorijska distanca i uobliče epske biografije.

\section{2. ,Mene stara proklinjala majka...”}

Proklinjanje je u usmenoj epici ponekad izosemično zaklinjanju uslovnoj kletvi, koja se aktivira u slučaju kršenja zabrane koju postavlja lice koje proklinje/zaklinje. Ono može biti u vezi s nekim opštijim kodeksom, junačkim, uglavnom:

Čuj me, silni neznani junače,

Mene moja proklinjala majka,

Kad me prvim pasom opasala,

A otac me triput proklinjao,

Kad mi za pas zatače oružje,

Da s' nikom ne uklonim s puta

(Marko Kraljević i Ognjanin Vuk, Vuk VI, 19: 37-42) ${ }^{6}$

5 „По песмама из збирки Вука Караџића (...) и, нарочито, по новијем певању о деспоту Вуку и трагичној судбини двојице Ђурђевића (...) Јерина својевољно даје кћер султану за жену и тиме изазива и пропаст државе и породичну трагедију". Љ. Пешикан-Љуштановић, Свете и проклете - жене из породие Бранковић у историји и усменој традищији, у: eadem, Станаја село запали. Огледи о усменој књижевности, Нови Сад 2007, стр. 102; Сf. Д. Ајдачић, ор. cit., стр. 20. „Daće ćercu đe prilike nije / S njom će propast zemlje i gradovi...” Кашиковић, стр. 141, према Љ. Пешикан-Љуштановић, ор. сіt., стр. 102.

6 Ah na viru, care gospodare!

Moja me je majka proklinjala,

Da ne vadim zaludo sablje

(Marko Kraljević i careva hazna, MH II, 12: 39-41);

Gospodare, care Sulejmane!

Jes' me stara proklinjala majka,

da naprazno ne izvadim ćordu

(Marko i car, SM 11: 90-92). 
ali je češće lične prirode i van određenih obredno-običajnih ili etičkih kompleksa. Zahtevi su po pravilu motivisani potrebama zapleta, kao u pesmi Đerzelez Alija i Vuk Despotović (Vuk VI, 59), gde se majčinim ,proklinjanjem" objašnjava zašto Zmaj-Ognjeni Vuk ne reaguje oštro na nejunački predlog kralja Matijaša da uzmakne pred opasnim protivnikom (Đerzelez Alijom) i odrekne se devojke (,Nemoj ići njemu na biljegu,/Ni mi vodi lijepu đevojku"):

Moli Boga za đavola tvoga,

Er me stara proklinjala majka,

Da te pazim kako baba svoga,

Jutros bih ti posjekao glavu (112-115) ${ }^{7}$.

Oni su, pri tom, često na granici fingiranih (ne zna se jesu li odista postavljeni ili je reč o improvizaciji/dovitljivosti lika):

A moj kume, dužde od Mletaka!

Mene stara proklinjala majka,

Da ne ljubim bradata junaka,

Već junaka mlada golobrada,

Kao što je Kraljeviću Marko

(Vuk II, 56: 201-205; Vuk VII, 24: 56-61; SM 19: 408-414)

ili su lažni, kao u pesmi Novljanin Alija i devet brata Vitkovića/Opet to isto (Vuk VI, 81), gde je ,proklinjanje"/zaklinjanje samo deo majčinog saveta Gruici Vitkoviću kako da se ponaša u neprijateljskom okruženju:

A ti reci, moje dite drago:

„Ne bojim se prijevare, pobro,

Već me j' stara proklinjala majka,

Da ne sjedem s braćom piti vino,

Dok me stara ne oženi majka"

(Vuk VI, 81: 86-90) ${ }^{8}$.

${ }^{7}$ Zaklinjanje ima analognu funkciju u Vuk VI, 24: 262-269: „Nemojte se, braćo, začuditi! / Evo ima tri neđelje dana / Da ne pijem ni vode ni vina, / Vina nemam, a vode ne smijem, / E me stara majka zaklinjala / Da ne pijem vode sa bunara, / Jer je voda bunar grozničava / Pa će mene uhvatit' groznica".

${ }^{8}$ Slično je i u varijanti ove pesme iz zbirke Sime Milutinovića:

Starica me proklinjala majka

kad starija piju vino braća, 
U datim situacijama ne aktivira se, dakle, moć reči (konkretna kletva), već predstava o imperativu poštovanja želje zaštićene zakletvom i neumitnosti ispunjenja kletve. Zaklinjanje/,,proklinjanje” koristi se kao sredstvo kojim junak efektno obrazlaže i štiti sopstveni postupak, jer jedino snagu kletve i moć zaklinjanja sve sukobljene ili potencijalno sukobljene strane (najčešće Srbi : Turci) prepoznaju kao dovoljno jaku motivaciju za delovanje i kao nešto što se ne sme dovesti u pitanje. Otuda se motiv zaklinjanja (fingirane zakletve) po pravilu javlja u momentima kada junak krši pravila ponašanja u tuđem prostoru: kada ne skida sa sebe oružje ili ne sjahuje s konja.

Zaklinjanje ima sličnu funkciju i u momentima kada treba obrazložiti postupak junaka koji se kosi s herojskim ili opštim etosom: ono što junak inače ne bi učinio, čini pod pretnjom ostvarenja kletve. U datim slučajevima po pravilu se aktivira najjača među kletvama - kletva majčinim mlekom $^{9}$, i to u dve osnovne sižejne situacije.

da ja s moga konja ne sjahujem,

ni od sebe da oružja davam

pa se bojim kletve materine

(Vitkovići, SM 129:75-79).

9 Zaklinjanje mlekom najčešće prati čin otkrivanja grudi, u čemu je Veselin Čajkanović video moćnu magijsku radnju: „Дојке, као и гениталија, имају мистички, демонски карактер, извесну супранормалну снагу. (...) Према томе, заклињање дојкама, или и сам obiectus pectorum, без речи, може имати велико магично дејство". В. Чајкановић, Obiectus pectorum, u: idem, Cтудије из српске религије и фолклора 1925-1942, Београд 1994, стр. 35. Motiv se, kako pokazuje Čajkanović, sreće na mnogo mesta u antici, kod Tacita, Ovidija, Euripida, Seneke, Haritona itd., a analogija s našim pesmama - i situaciona (majka odgovara sina od opasnog poduhvata, jer strahuje za njegov život, up. primere niže) i formalna - najupadljivija je u Ilijadi (22: 79-85 - prev. M. Đurić):

Mati pak lijući suze na drugoj ridaše strani;

nedra otkrije ona i rukom izvadiv dojku

očiju suznih sinu progovori krilate reči:

„Mleko, Hektore sinko, ne prezri, no sažali mene,

ako te ikada dojkom odojih i plač ti utišah:

toga seti se, mili moj sine, i stojeć' za bedemom gradskim

dušmana odbijaj besnog, al' spreda ne bori se s njime!".

O materinoj kletvi/kletvi materinim mlekom u kontekstu balkanske epike i lingvistike videti: Ж. Малобабић, Сакрални карактер мајчиних груди. Од обреда до вербалног текста и ријечи, „Српски језик” бр. IV/2, 1999, стр. 847-862. 
U prvoj se kompromituje junački status (odustajanje od megdana, isprošene devojke i sl.):

majčina kletva mlekom/,,(h)ranom”

Kad to čula lijepa kaduna, Mila majka bega Ljubovića, Ona pisnu kao ljuta guja; Iz njedara dojke izvadila, A ovako sinu govorila: „O moj sine, beže Ljuboviću, Ako ne ćeš majku poslušati, Dati slugu i dorata svoga, Da prevedu lijepu djevojku Od Zagorja do Mostara b'jela, Haram tebi moja hrana bila, Kojom te je majka odhranila" (KH I, 07: 68-79). nejunački postupak

Beg Ljubović odustaje od ženidbe ćerkom Čengić alaj-bega i od megdana sa Mostarlijom Mujom i šalje svog slugu i konja da suparniku dovedu nevestu (,Muka spremit slugu i dorina, / A još viša ne poslušat majke. / Sve mislio na jednu smislio: / Bolje dati slugu i dorina, / Nego svoju ne poslušat majku, / Jer se bojat teška eksikluka"; 86-91). $\mathrm{Na}$ isti način, beg Ljubović odustaje od megdana i ženidbe jer se ,prepao materine kletve" (Vuk VII, 23: 100-127).

Druga tipska situacija u kojoj se majčina zakletva mlekom postavlja kao imperativ delovanja jeste neljudska, neetična reakcija junaka i uglavnom je vezana za jedan od obrazaca koji varira temu „majke krvnice” (svekrva pokušava da naudi snahi):

majčina kletva mlekom/,,(h)ranom”

Kad sasluša majka lakrdiju, Raspučila na prsi kavada, A razmače vezenu košulju, Izvadila obadvije dojke, Pa Jovanu sinu govorila: „O Jovane, neposlušni sine! Ako staru ne poslušaš majku, Gubalo te materino ml'jeko, Razgubalo, pa te ošogalo, Što s'iz ovih dojak' posisao, No pogubi tvoju vjernu ljubu, Boljom ću te, sine, oženiti” (Vuk VI, 02: 38-49). neetičan postupak

Jovan šalje brata Bogdana da mu ljubu odvede u šumu i zakolje je (,,Sve mislio, dok zlu izmislio: / «Volim moju oštetiti dušu, / Pak se kajat' od mojih gr'jehova, / Nego majci hatar oštetiti, / I majčinu kletvu ne slušati»”; 55-59). 
S druge strane, majčinom kletvom, kao najdelotvornijom ${ }^{10}$, etički kodeks se i štiti, mada se u tu svrhu aktiviraju i kletve sveštenstva (hrišćanska patina), posebno kada je reč o tabuisanju incesta ${ }^{11}$ :

pravda

Kol'ko Marko težio na pravdu,

Tol'ko moli Jevrosima majka:

„Marko sine jedini u majke!

Ne bila ti moja rana kleta,

Nemoj, sine, govoriti krivo

Ni po babu, ni po stričevima,

Već po pravdi Boga istinoga;

Nemoj, sine, izgubiti duše;

Bolje ti je izgubiti glavu,

Nego svoju ogr'ješiti dušu"

(Vuk II, 34: 124-133). sprečavanje incesta

Kad eto ti đakona Jovana

I njegove đece trista lude,

Ovako su riječ besjedili:

„Dobro jutro, sirota Roksandro!

A da Bog da i Bogorodica,

Ak' uzela mila brata svoga,

Božja od vas ne ostalo traga,

Do van zmije i kamena stanca!"

(Vuk II, 27: 94-101).

${ }^{10}$ Ta je delotvornost i u osnovama analogne forme blagoslova, koji se traži pred odlazak u okršaj (potencijalna smrt) ili pred smaknuće (realna smrt):

Eto njega niz bijelu kulu,

Do gotova konja dopanuo;

Svoju majku po dojkama ljubi:

„Moja mati, halali mi hranu,

Ako meni suđen sahat dođe,

Te poginem u Janoku gradu"

(KH II, 52: 422-427).

Majku svoju u dojke poljubi:

„Moja majko, halali mi ml'jeko"

(KH I, 23: 121-122)

(Slično i SM 150: 382-387).
Bogom braćo, dva dželata mlada!

Vodite me carici materi,

Da mi prosti i muku i ranu:

Ranu njenu, što me je ranila;

Muku njenu, što je promučila,

Dok je mene ona odranila

(Vuk II, 30: 301-306).

Anđelija, moja mila majko,

Blagoslovi mene, moja majko,

Prosti mi, majko, i muku i ranu

Da bi ti se rastavio s dušom!

(SANU II, 88: 192-195).

${ }^{11}$ Incest je jedan od najjače tabuisanih, ali ne i jedini tabuisani vid ponašanja. Majčinim mlekom štiti se i obredni kodeks:

Majka vadi dojke iz nedara:

„Ne ubila t' rana materina!

Nemoj danas krvi učiniti,

Danas ti je krsno ime krasno:

Tko ti danas u dvorove dođe,

Napoj žedna, a narani gladna

Za dušicu tvoji roditelja

i za zdravlje tvoje i Jelino"

(Vuk II, 72: 82-89). 
Kletva mlekom javlja se, najzad, i u nešto drugačijem - gotovo parodijskom - kontekstu, kao protivteža inadžijskoj i teškoj naravi Marka Kraljevića, čime se taj aspekt Markovog lika komički razobličava. Kada zbog uvrede da je ,ženska strašljivica” (jer svom pobratimu, begu Konstantinu, predlaže da beže iz Kratova: „Kratovo je vrlo pobedljivo, / Ludo ćemo pogubuti glave"), Marko kasnije odbije da pobratima spase sa vešala (,Šta će njemu ženska strašljivica, / Šta li bi mu u pomoći bio”), Jevrosima poseže za kletvom, kao jedinim načinom da Marka navede na delovanje:

\footnotetext{
Al' besedi Jevrosima majka:

„Čedo moje, Kraljeviću Marko,

Idi, Marko, te iskupi bega".

Sagnula se Jevrosima majka,

Sagnula se dole po trpezi,

I uzima dva mermer kamena,

Izvadila bele dojke svoje,

Pa udara kamen po kamenu

I zaklinje Kraljevića Marka:

„Sine Marko, moje čedo drago,

Tako mi te kamen ne ubio,

I tako ti rane materine,

Idi, Marko, te iskupi bega"

(Vuk VI, 18: 54-66).
}

U određenim situacijama i iskazi formalno uobličeni kao kletve poprimaju značenje zaklinjanja. Iako nema kondicionalnih rečenica („Ak' uzela mila brata svoga”; „Ako nećeš svakom sudit pravo”; „Ako staru ne poslušaš majku”), niti imperativa (,Nemoj, sine, govoriti krivo...”; „Idi, Marko, te iskupi bega"), uslov ispunjenja kletve se podrazumeva, a dejstvo kletve poništava se ponašanjem kakvo očekuje i priželjkuje strana koja kune:

kletva

Zaspa Jovo kako jagnje ludo,

Al' đevojka spavati ne može,

Okreće se po meku dušeku,

Ud'ri Jova rukom uz obraze:

„O Jovane, ne digao glave!

Zar ti žališ tvojega đogata? postupak koji je poništava

Kad to viđe dijete Jovane,

On zagrli Turkinju đevojku,

Poljubi je tri-četiri puta,

Da tko broji, i više bi bilo.

Pa zaspaše đece obadvoje

(Vuk III, 19: 79-83). 
Da Bog da ga uzjahali Turci!

A moj đerdan popili hajduci!"

(Vuk III, 19: 71-78).

Kad se prenu dijete Jovane,

Tanku kulu ogrijalo sunce,

Veli njemu Turkinja đevojka:

Reče riječ dijete Jovane:

„Oj đevojko, mrtvi san zaspala!

„Ne boj mi se, dijete Jovane!

Na pendžere ogrijalo sunce,

Ja bih tebe mogla ostaviti

I godinu dana bijelijeh

Hoće mene Turci pogubiti”

U našemu dvoru bijelome,

(Vuk III, 19: 84-89).

Da ne znade ni otac ni majka"

(Vuk III, 19: 90-95).

Na sličan način - kao sankcioni mehanizam - deluje i hipotetična, tek moguća i pretpostavljena kletva:

Al' govori Kraljeviću Marko:

„Fala tebe, care poočime!

Kad ti staneš mene dvore gradit',

Mene hoće sirotinja kleti:

«Gle kurvića Kraljevića Marka!

Oni su mu dvori izgoreli,

A ovi mu pusti ostanuli!»

Da m’ učiniš agom haračlijnskim,

Ja harača pokupit' ne mogu

Dok ne svežem ništa i uboga,

Pa će mene sirotinja kleti:

«Gle kurvića Kraljevića Marka!

Ono mu je blago odnešeno,

A ovo mu ostanulo pusto!»"

(Marko Kraljević i Mina od Kostura, Vuk II, 62: 218-231).

Na suprotnom polu nalazi se pak kletva ,ispražnjena” od njenih tradicionalnih značenja sa sasvim specifičnom poetskom funkcijom. Njena nedelotvornost u usmenoj epici figurira kao sredstvo glorifikacije junaka i to onih najvećih, čiji osvetnički bes ni kletva demonskog bića - čak ni u gori, koja je prvorazredni demonski hronotop ${ }^{12}$ - ne može zaustaviti (Marko Kraljević $i$ vila brodarica, MH II, 02: 92-112) ${ }^{13}$.

${ }^{12}$ М. Детелић, Митски простор и епика, Београд 1992, стр. 57-87.

${ }^{13}$ Prethodni primeri (majčine kletve), kao i brojne kletve nevesti/devojaka, vila, sestara, kuma, maćeha, ljuba (setimo se kadune Kulin-kapetana u epilogu pesme Boj na Mišaru) 
Generalna predstava o moći i delotvornosti kletve, svojstvena sistemu mišljenja tradicionalnog čoveka, našla se u usmenoj epici u osnovama sasvim konkretnih sižejnih funkcija: kletvom se, sem očekivane predikcije događanja (kojom se na sižejnom planu determiniše izbor i nizanje motiva/narativnih sekvenci), motivišu i postupci junaka koji sa stanovišta epske poetike nisu uzoriti ili, sa stanovišta ideološke i istorijske pozicije/dominacije - nisu konzistentni. Na taj način ,spasava se” integritet epskog junaka ili logika pripovedanja, a u situacijama kada značenja nadilaze konkretnu varijantu - i pozicija likova u širem istorijsko-epskom kontekstu. Zbog semantike baštinjene iz najarhaičnijih slojeva kulture, poseban modelativni potencijal zadobila je kletva majčinim mlekom, koja se, upravo zbog visoke tabuisanosti/imperativa poštovanja, stopila sa analognim formama - blagoslovom i zaklinjanjem („Moja majko, halali mi ml'jeko" KH I, 23: 121-122; up. KH II, 52; Vuk II, 30; SANU II, 88 i sl.). Poricanje delotvornosti kletve - u opreci s principom mišljenja tradicionalnih kultura - našlo je pak uporište u globalnom epskom sistemu koji, barem u najstarijim slojevima pevanja, postupke junaka posebne kategorije ne procenjuje sa stanovišta etičnosti već mitske nužnosti. Da bi dospeo u tu kategoriju, junak mora imati funkciju zastupnika sociuma u sukobu sa prirodom, odnosno ljudskog sveta u sukobu sa demonskim. A da bi ispunio uslove koji se za takvu ulogu traže, i sam mora biti makar jednim delom na „onoj strani” (Marko Kraljević, dijete Sekula, Miloš Obilić, Zmaj Ognjeni Vuk itd.).

itd., svojom brojnošću u znatnoj meri relativizuju zaključke Davora Nikolića izvedene na osnovu 109 odabranih pesama iz Bogišićevog zbornika: „Tako imamo 79 muških naspram 33 ženska adresata (autor misli na adresante - prim. M.D. i L.D.), odnosno gledano u postotku 70\%: 30\%. To potpuno odbacuje pretpostavku da u epskoj poeziji žene kunu češće nego muškarci, dapače. I tu bi se moglo govoriti o djelomičnom ograničavanju glasa (gdje oni drugi sada postaju žene) ili o nemogućnosti ostvarenja ženskih likova kao subjekata u epskome svijetu" (D. Nikolić, Struktura i funkcija kletvi u usmenoj i pisanoj epici, „Narodna umjetnost” br. 47/2, 2010, str. 153). Nikolićev tekst, s ambicioznim, disertabilnim naslovom - Struktura i funkcija kletvi u usmenoj i pisanoj epici - nažalost ne „pokriva” polje usmene (kao ni pisane) epike. Analiza obimnijeg korpusa dala bi znatno drugačije rezultate. 


\section{Izvori}

ЕР: Ерлангенски рукопис старих српскохрватских народних песама, издао Герхард Геземан, Сремски Карловци 1925.

EH: Muslimanske narodne junačke pjesme, sakupio E. Hadžiomerspahić, Banja Luka 1909.

KH I-II: Narodne pjesme muslimana u Bosni $i$ Hercegovini, sabrao K. Hörmann, knjiga I-II, Sarajevo 1933.

KH III: Narodne pjesme muslimana u Bosni i Hercegovini. Iz rukopisne ostavštine Koste Hörmanna, red. Đ. Buturović, Sarajevo 1966.

MH I-IX: Hrvatske narodne pjesme. Odio prvi. Junačke pjesme, ur. I. Broz, S. Bosanac, Zagreb 1890-1940.

SANU II-IV: Српске народне пјесме из необјављених рукописа Вука Стеф. Карацића, Београд 1974 <http://scc.digital.nb.rs/collection/epska-sanu> [preuzeto: 3.10.2012]

SM: С.М. Сарајлија, Пјеванија црногорска и херцегговачка, прир. Д. Аранитовић, Никшић 1990 [Пјеванија иерногорска и хериеговачка, сабрана Чубром Чојковићем Церногорием. Лајпциг 1837].

Vuk I-IV: Сабрана дела Вука Карацића, Српске народне пјесме, издање о стогодишњици смрти Вука Стефановића Караџића 1864-1964 и двестогодишњици његова рођења 1787-1987, Београд 1986-1988, <http://scc.digital. nb.rs/collection/epska-vuk-I> [preuzeto: 3.10.2012].

Vuk VI-IX: В.С. Караџић, Српске народне пјесме 1-9, Београд 1899-1902. 
